\title{
Ecological Site Development: A Gentle Introduction
}

\section{By Kendra Moseley, Pat L. Shaver, Homer Sanchez, and Brandon T. Bestelmeyer}

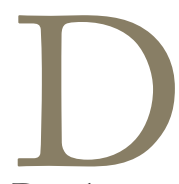
eveloping ecological sites requires knowledge of plant community dynamics and species interactions, as well as interactions among plants and soil, climate, and landscape features. Developers must know what questions to ask at the beginning of the development process, what data to collect in the field, and how to use the data to create and test ecological site concepts. Ecological sites provide a general ecological foundation for management. Ecological sites bring together several ecological concepts, including plant-soil interactions, succession and climax, nonequilibrium in community structure, and ecological gradients and spatial heterogeneity. Ecological sites integrate a variety of information sources, including inventory data that link plant communities to soil profiles and landscape position, historical reconstructions, and management considerations based on local knowledge and monitoring data. A well-organized plan is essential to properly develop a set of ecological sites. The steps in such a plan discussed here include 1) asking a set of general questions regarding ecological sites, 2) conducting literature research and field visits for reconnaissance, 3) specifying initial ecological site concepts, 4) collecting inventory data, 5) analyzing and interpreting the data collected, and finally 6) refining ecological site concepts and compiling associated information into ecological site descriptions (ESDs; Fig. 1).

\section{Step 1: Ecological Questions}

The set of ecological sites defined for an area should be viewed as answers to a series of questions. Generally, the questions are as follows:

1) What should be the reference conditions for specific land areas, what are the characteristics of the reference conditions, and what ecological processes lead to the persistence of reference conditions?

2) What changes in vegetation and soils can occur relative to the reference conditions, including easily reversible changes (community pathways between community phases) and more difficult to reverse changes (transitions to alternative states)? How do they occur via natural and human-caused processes, and how can they be reversed with management and restoration?

3) How do reference conditions and changes in vegetation vary with climate, topography, and soils?

The answers to questions 1) and 2) define the ecological properties of the ecological sites, including their plant and animal communities, community dynamics, and uses. The "ecological site concepts" establish the unique identities of different ecological sites due to the correlation of differences in geophysical and ecological properties.

The answer to question 3) leads to the set of ecological sites in a landscape and defines their geophysical properties, including climate, topography, and soils. The geophysical properties determine the resources potentially available to plants (and therefore the net primary production and community composition of plants), as well as the natural disturbance regime (such as fires, floods, or droughts) and their effects on plants and soils. ${ }^{1}$ Variations in climate, topography, and soils (and related attributes such as hydrology) are used to distinguish the ecological sites that co-occur in different parts of the landscape and to describe the distinctive characteristics of each site.

In the following steps, we describe how to develop ecological site concepts, test them, and define the properties of ecological sites. It is important to recognize at the outset that ecological sites are an imperfect solution to breaking up what in reality is continuous variation in ecosystems over space and time. There is no cookbook; defining ecological sites is a blend of art and science.

\section{Step 2: Research and Reconnaissance}

For all areas within the focal region (usually a Major Land Resource Area [MLRA] or Land Resource Unit [LRU]), it is useful to begin with an exhaustive review of the published research and mapping for the region (including its geology, soils, climate, vegetation, and wildlife), interviews to obtain expert knowledge (for example, with the "old timers"; see Knapp et al., this issue), and collation of 


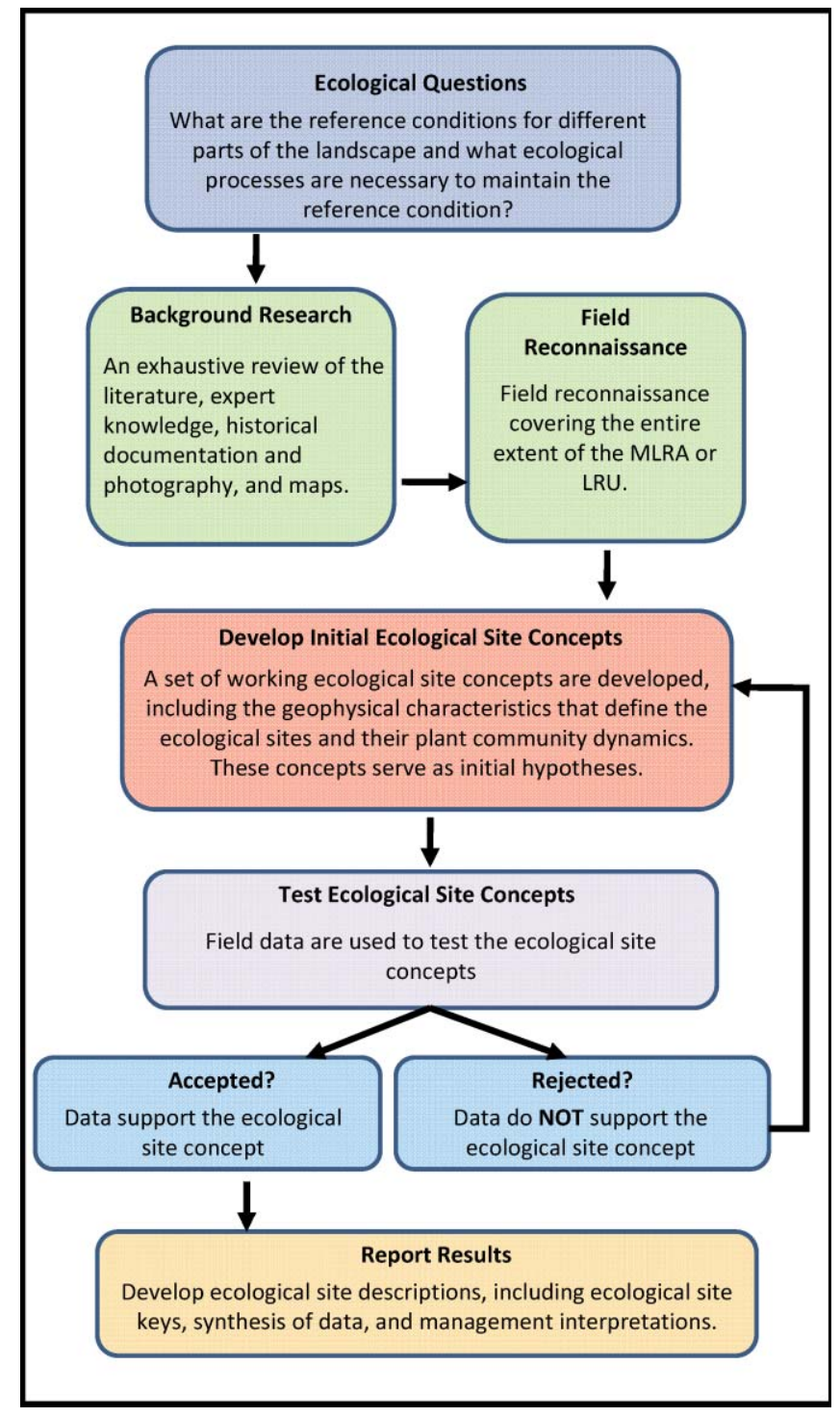

Figure 1. A summary of the stepwise approach to ecological site development.

historical documentation, photography, and maps. This research effort should seek to document evidence for reference conditions, the key ecological processes and disturbances that occur in reference conditions, the identity of alternative states, and the drivers (such as grazing or climate cycles) that lead to shifts among communities and states. In general, the developer should be aware of all of the current research being conducted in the region. One product of this research effort should be rudimentary groupings of climate zones/elevation zones, parent materials, soil properties, and vegetation and wildlife communities. It also can provide information on some of the common land uses and management concerns that occur within the general groupings. For example, valley oaks (Quercus lobata) commonly are associated with Santa Barbara sedge (Carex barberae) in more open savannas and Fremont's cottonwood (Populus fremontii) in riparian forests. They are commonly found on upper stream terraces and floodplains on deep, well-drained alluvium and the water table should be within reach of valley oak roots. Soil textures are often loamy sands and gravelly loamy sands. Valley oak habitat is used by numerous animal species, including cavity-nesting and cavity-storing birds. The most common issues facing valley oaks include removal of the natural hydrologic regime (flooding), habitat loss for agriculture and housing, rodent and deer predation of seedlings, lack of open niche space for new seedlings, and shading created by the older valley oak canopy.

The literature-based research should be combined with initial field reconnaissance visits covering the entire extent of the focal region. This will ensure that the complete range of variation across the region is considered in developing ecological site concepts and that the ecological sites adequately reflect the conditions that users may encounter. Inviting specialists and other knowledgeable individuals to the field to participate in the reconnaissance can offer valuable information about historical events, vegetation-soil relationships, and the origins of landscape patterns that are a consequence of the two. It is essential at this stage to take detailed field notes describing the dominant vegetation, surface soil conditions, land uses, elevation, and aspect, and to dig shallow soil pits (using an auger or shovel) to identify general soil properties. Observations can be collected systematically, including Global Positioning System (GPS) waypoints and photographic records. A "low-intensity" or reconnaissance data form can be used for this purpose (see http://usda-ars.nmsu.edu/esdResources.html). The field notes can be used to establish straightforward ecological site concepts and to note areas that are going to be more difficult to disentangle and will require more field data.

\section{Step 3: Developing Ecological Site Concepts}

After conducting the research and reconnaissance, the developer should be able to use the information to specify a series of initial ecological sites with draft state-andtransition models (herein referred to as STMs, see Bestelmeyer et al., this issue). The set of draft ecological sites and STMs are effectively a hypothesis about how to subdivide the MLRA or LRU that can be further tested using inventory data or other new data. The ecological site concept should clearly specify the climatic, topographic, and soil properties that distinguish the site from others (Table 1). The draft STM should describe at a minimum the properties of the reference state and its component plant communities and dynamic soil properties. In addition to the reference state, other known states and community phases occurring on the site also can be described. Ecological site concepts should be developed to represent all rangeland and forestland areas within the MLRA or LRU. In some cases, the boundaries of the MLRA or LRU will be adjusted in the process.

These initial ecological site concepts do not need to be detailed, but they need to identify clearly the factors that 
Table 1. An example of some general ecological site concepts created from initial field reconnaissance

\begin{tabular}{|c|c|c|c|c|c|c|c|c|c|}
\hline $\begin{array}{l}\text { Preliminary } \\
\text { ecological } \\
\text { site }\end{array}$ & $\begin{array}{l}\text { Elevations } \\
\text { (ft) }\end{array}$ & Landform & Geology & Aspects & Slopes & $\begin{array}{c}\text { Soil } \\
\text { texture }\end{array}$ & $\begin{array}{l}\text { Soil } \\
\text { depth }\end{array}$ & $\begin{array}{l}\text { Dominant } \\
\text { reference } \\
\text { vegetation }\end{array}$ & $\begin{array}{c}\text { Data collection } \\
\text { needs }\end{array}$ \\
\hline 1 & $1,500-3,500$ & Mountains & Granite & $\begin{array}{l}\text { South } \\
\text { West }\end{array}$ & Steep & Sandy & Deep & $\begin{array}{l}\text { Chamise- } \\
\text { buckbrush }\end{array}$ & $\begin{array}{l}\text { High variation: } \\
\text { extensive data } \\
\text { needed }\end{array}$ \\
\hline 2 & $1,200-3,800$ & Mountains & Granite & $\begin{array}{c}\text { North } \\
\text { East }\end{array}$ & Steep & $\begin{array}{l}\text { Loamy } \\
\text { sand }\end{array}$ & $\begin{array}{l}\text { Moderately } \\
\text { deep }\end{array}$ & $\begin{array}{l}\text { Bigberry } \\
\text { manzanita- } \\
\text { scrub oak }\end{array}$ & $\begin{array}{l}\text { High variation: } \\
\text { extensive data } \\
\text { needed }\end{array}$ \\
\hline 3 & $500-1,000$ & $\begin{array}{l}\text { Upper } \\
\text { stream } \\
\text { terraces }\end{array}$ & Rhyolite & Neutral & Flat & $\begin{array}{l}\text { Sandy } \\
\text { clay loam }\end{array}$ & Deep & $\begin{array}{l}\text { Valley oak- } \\
\text { sedge }\end{array}$ & $\begin{array}{l}\text { Low variation: } \\
\text { minimum data } \\
\text { needed }\end{array}$ \\
\hline 4 & $1,500-3,500$ & Footslopes & $\begin{array}{l}\text { Volcanic } \\
\text { breccia }\end{array}$ & $\begin{array}{c}\text { North } \\
\text { East }\end{array}$ & Steep & $\begin{array}{l}\text { Sandy } \\
\text { loam }\end{array}$ & $\begin{array}{c}\text { Shallow to } \\
\text { bedrock }\end{array}$ & $\begin{array}{l}\text { Hollyleaf } \\
\text { cherry- } \\
\text { toyon }\end{array}$ & $\begin{array}{l}\text { High variation: } \\
\text { extensive data } \\
\text { needed }\end{array}$ \\
\hline
\end{tabular}

allow the ecological site to be distinguished from others in the field (Table 1). In doing so, it is useful to consider the range in characteristics of factors that vary at different spatial scales, working from relatively broad scales of elevation and climatic variations to the finer-scale soil properties. Vegetation should not be a primary ecological site criterion because it can be easily manipulated by both natural and human-caused disturbances and it is therefore highly variable. Nonetheless, certain plant species can be used to assist in ecological site definition and identification because they provide clues to soil and climatic conditions. The ecological site concept should be developed, however, using geophysical attributes that enable identification of the ecological site even without vegetation on the site.

Where changes in soils, aspect, topography, or moisture conditions are abrupt, the boundaries of the ecological site concepts will be obvious. Where soils and plant communities change gradually along broad environmental gradients in areas of fairly uniform topography, ecological site distinctions are more difficult to specify and might require data collection before solid ecological site concepts can be developed. ${ }^{1}$ Even when climatic, soil, and topographic variations are continuous, forcing these variations into discrete ecological site concepts allows them to be recognized as distinct kinds of land with distinct management needs. In order to have a reasonable and useful number of ecological sites, site concepts necessarily encompass some degree of variation in climate, topography, soils, and therefore ecological potential. This variation can be represented using ranges for each attribute.

Traditionally, the average range in the minimum and maximum is used to describe a site concept rather than the absolute minimum and maximum ranges. In other words, if the site is almost always found on 30-75\% slopes, but rarely can be found on $8 \%$ slopes, the site concept is described as having $30-75 \%$ slopes rather than $8-75 \%$ slopes. The absolute range and frequency distribution of observed conditions also can be reported within the ESD. Thus, even though some exceptions to the reported average range might be encountered in the field with regard to a particular attribute, values for other attributes should be able to lead the user to the correct ecological site. Ecological site concepts are multivariate constructs. They are built from the relationships of several interacting attributes that collectively produce similar environments for plant communities.

Ecological site concepts rely on the correlation of changes in plant environments with changes in climate, soil, and topographic properties. Large differences in those properties usually result in large differences for plant communities, producing easy ecological site distinctions. Sometimes, however, minor differences in soil properties can result in enough variation in resource levels to produce important differences for plants. For example, three ecological sites were identified in an area within MLRA 15 (Central California Coast Range; Fig. 2), two of which were developed for chamise chaparral-dominated hill slopes. On the north- and eastfacing slopes the soils were sandy, mixed, thermic Entic Haploxerolls and the cover was a mixture of chamise (Adenostoma fasciculatum), buckbrush (Ceanothus cuneatus), and manzanita (Arctostaphylos spp.). On the south- and west-facing slopes, the soils were sandy-skeletal, mixed, thermic Entic Haploxerolls and the cover was almost 100\% chamise. Thus, differences in gravel content in the soil profile associated with changes in aspect cause a remarkable shift in plant species composition, illustrating how even small soil-topographic differences can affect vegetation. Conversely, in areas of high rainfall, even large differences in the properties of the soil profile might have little effect on plant community composition or management.

The other side of the coin in ecological site concept development is to recognize what differences in plant community structure or management are important enough to warrant distinct ecological sites. In general, the ecological site developer should have a clear understanding of management issues 


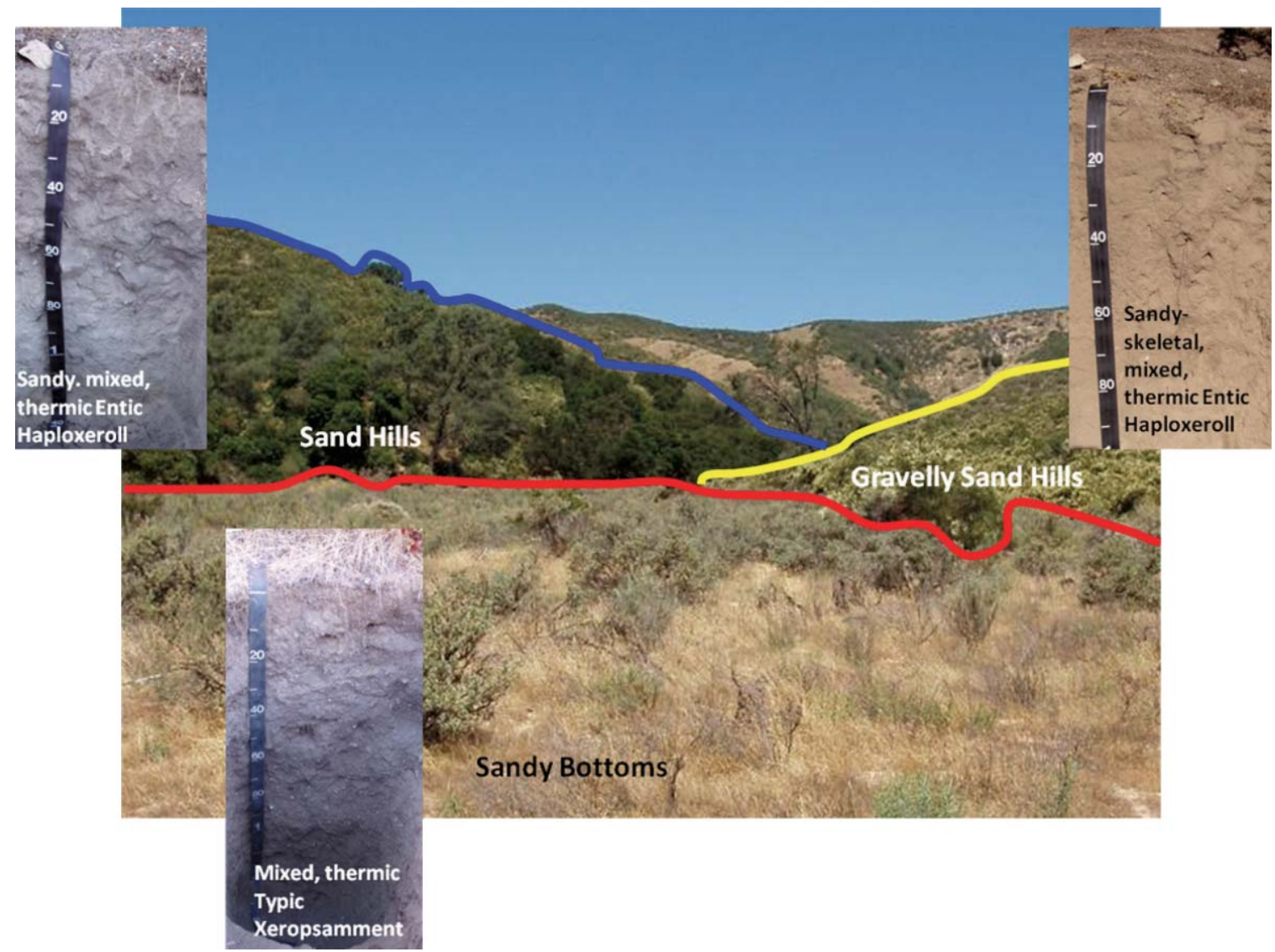

Figure 2. Ecological sites in Major Land Resource Area 15 in California, illustrating how differences (major and minor) in soil properties can create vegetation composition differences.

within the MLRA or LRU to recognize important differences. Some general guidelines are that shifts in the dominance of common plant species, uncommon species of management importance, changes in overall production, and changes in the sensitivity of dominant plants to disturbance are used to justify different ecological sites (Box 1). Minor differences in production (e.g., $<20 \%$ ); changes in the abundance of ephemeral, uncommon, and less important species; or shifts in abundance of very similar but common species might not warrant a distinct ecological site. The soil/topographic variations producing minor variations can be described within the ESD narratives, however. General guidelines for significant differences are described in the USDA National Range and Pasture Handbook. ${ }^{2}$

When developing site concepts, it is useful to emphasize the characteristic plant community of the reference state (i.e., the reference community phase). It commonly is a late successional plant community. This is the community that can be used to define the attributes of site potential because it is relatively unaltered from pre-European conditions (in the US) and contains the full complement of species that historically occupied the site. Observations of plant-soil relationships in near-reference conditions are desirable because the effects of soils on plant community development can be obscured by disturbance. When areas approximating reference community phases are unavailable, then persistent (e.g., unpalatable shrubs), dominant, or relict species can be used to recognize important differences in plant environments that would likely affect all species potentially present in the community. In some cases, even without clear differences in existing vegetation, distinct ecological sites

Box 1. Some initial guidelines for determining significant differences between ecological sites (see NRCS National Range and Pasture Handbook ${ }^{2}$ )

Presence (or absence) of one or more species that make up $10 \%$ or more of the reference plant community by air-dry weight.

A 20\% (absolute) change in composition, by air-dry weight, between any two species in the reference plant community.

A difference in average annual herbaceous production of:

$-50 \% @ 200-500$ pounds/acre

-30\%@500-1,000 pounds/acre

$-20 \% @ 1,000$ pounds/acre or greater 


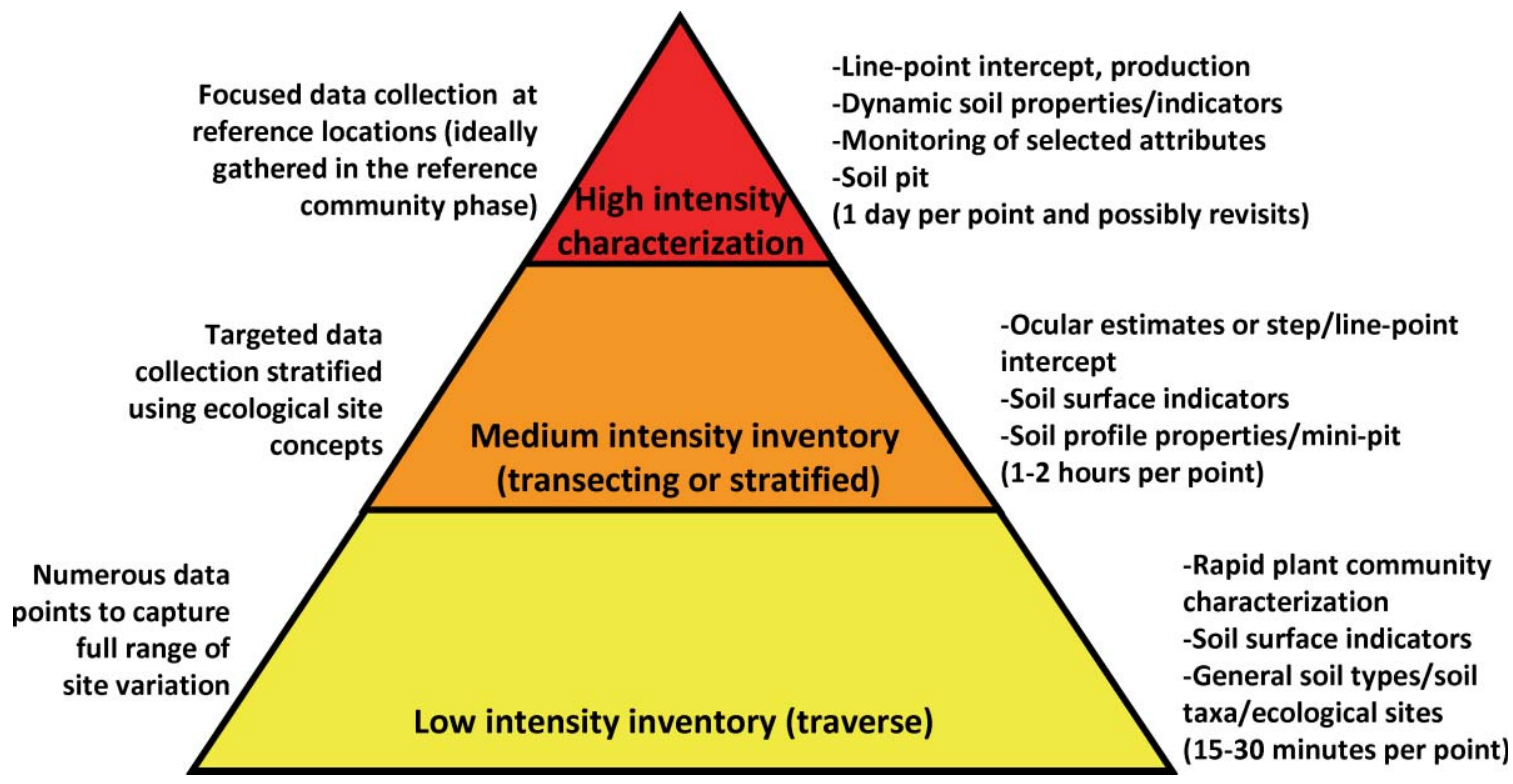

Figure 3. A data collection strategy for ecological sites beginning with many low-intensity data points during reconnaissance and culminating in intensive data collection in established ecological sites.

can be justified when the magnitude of differences in soil properties suggests that they will affect use and management. It is important to attempt to distinguish managementrelated from soil-related differences during reconnaissance.

Building useful ecological site concepts from the relationships of multiple soil and plant attributes is the critical task in the early stages of ecological site development (Table 1). These concepts structure ecological site hypotheses and data collection priorities. Essentially, when arriving in a new area, the initial site concepts are used to test whether or not new site concepts are needed, including revisions to site criteria, the addition of new ecological sites, or combining two sites into one.

\section{Step 4: Collecting Data}

Ecological site concepts are used to design field inventory for testing the concepts. The concepts are used to stratify samples across the MLRA or LRU using maps or aerial photography; even Google Earth can be used. A slopes map, aspect map, and/or geology map can be reviewed to delineate preliminary ecological sites on the landscape and then to locate a series of sampling points within each site. Some sample points should be selected randomly but others can be deliberately selected to focus on reference communities or areas where the ecological site is in doubt (analyses of these two types of data should be kept separate). Such inventory is generally of "medium intensity" (Fig. 3); that is, more data are collected than in reconnaissance but less than might be needed to characterize all of the properties of reference plant communities. ${ }^{1,3}$ Because every system is different and can range from fairly homogenous to extremely heterogeneous, it is important to determine what data collection strategy will best capture the variations across the landscape. Generally, in this step we recommend that data be gathered in restricted areas around fixed points (e.g., a $20 \times 20 \mathrm{~m}$ or $1 / 10$ th acre plot) so that vegetation and soils data can be related to one another in the same locations. If longer transects (e.g., $100 \mathrm{~m}$ ) are used, soil properties might vary considerably along the length of the transect, complicating testing of plant-soil relationships. The specific protocol or combination of protocols used should be sufficient to recognize soil diagnostic horizons and their properties (e.g., soil texture, soil texture modifiers, soil depth to an argillic, calcic, or water- or root-restrictive horizon), topographic features (slope and aspect), variations in plant cover, and soil surface properties (see Duniway et al., this issue). Information on current and past land uses and disturbances and land management also should be recorded in order to distinguish effects that are due to state changes that occurred in the past. Each data point also should include at least one picture and a GPS waypoint using a standardized coordinate system across the project.

\section{Step 5: Analyzing Results}

After collecting inventory data at a sufficient number of locations, the body of data can be examined to see if it supports the initial ecological site concepts or if modifications to the site concepts are necessary. The data might support an initial set of ecological site concepts, but the concepts might need to be altered slightly and additional data gathered to quantify concept boundaries. For example, data for an initial ecological site were collected at 30 different locations that were selected using a slope/aspect map (created using a digital elevation layer in a Geographic Information System). Twenty of these locations supported the ecological site concept, that is, the soil, topographic, and plant community 
relationships were concordant with those described in the initial concept (e.g., ecological site 4 in Table 1). The concept specified north- and east-facing aspects, 30-75\% slopes, and soils with sandy, sandy loam, and gravelly sandy loam soil surface textures that were very shallow to shallow to volcanic bedrock with an estimated annual production of 1,000-1,300 pounds/acre. The remaining 10 locations, however, did not fit within this concept. In these samples, the soils were all moderately deep, slopes ranged from $15 \%$ to $45 \%$, and the annual production was estimated to be much higher at over 1,500-2,000 pounds/acre. The surface soil textures and aspects, however, were similar. The 20 samples that supported the initial ecological site concept can be used to refine the ecological site concept and to select areas for higher intensity data collection (see below), but the remaining 10 samples should be used to consider an additional ecological site. Additional medium- or highintensity samples should be collected until a set of repeatable concepts can be identified and described.

More detailed descriptions of vegetation and soils ${ }^{3}$ sometimes can help in refining ecological site concepts when less detailed procedures are unable to quantify the soil or topographic attributes causing variation in plant communities (and excluding state change as a cause). Full descriptions of the soil horizons (usually to a depth of $1 \mathrm{~m}$ ) and samples of the major soil horizons should be gathered for lab analysis (e.g., soil textures, $\mathrm{pH}$, salinity), especially when changes in soil chemistry are thought to be important. Consideration of landscape context, such as the properties of surrounding areas, might require use of digital elevation models or aerial imagery (e.g., when surface hydrology is an important factor). Line-point intercept data can be used to provide more precise estimates of vegetation cover, as well as soil surface characteristics such as bare ground, fragment, or biological soil crust cover. The additional, more intensive data can then be used to reassess ecological site concepts.

With the body of data in hand, the general guidelines discussed above can be used to revisit ecological site concepts and to quantify the specific distinctions between ecological sites. At the end of the process, the ESD user should be able to use a key to identify ecological sites based on climatic, soil, and topographic properties

Table 2. Example of a partial ecological site key, developed for Montana rangeland ecological sites

A. Site receives additional effective moisture

1a. Soil saline (EC $>4$ within surface 4 inches) and water table $>24$ inches

2a. Seasonal high water table 24-42 inches from ground surface; salt-tolerant plants dominate site ... Saline Subirrigated (SSb)

$2 b$. Seasonal high water table $>42$ inches from ground surface; salt-tolerant plants dominate site; site regularly receives more than normal soil moisture because of run-in or stream overflow ... Saline Overflow (SOv)

1b. Site not as above

3a. Site is a closed depression with run-in ... Pothole (Ph)

$3 b$. Site is not a closed depression

4a. Seasonal high water table $>42$ inches from ground surface; site regularly receives more than normal soil moisture because of run-in or stream overflow ... Overflow (Ov)

4 b. Seasonal high water table $<42$ inches from ground surface

5a. Soil organic (organic surface $>8$ inches thick) ... Wet Meadow, Organic (WMO)

5b. Site located in the flood plain

6a. Soil very poorly or poorly drained

7a. Very poorly drained ... Riparian Wet Meadow (RWM)

7b. Poorly drained ... Riparian Meadow (RM)

6 b. Soil not very poorly or poorly drained

8a. Soil sandy-skeletal to within 20 inches of surface ... Wet Gravelly (WGr)

8b. Soil not sandy-skeletal ... Riparian Subirrigated (RSb)

5c. Site not located in flood plain

9a. Soil very poorly or poorly drained

10a. Very poorly drained ... Wet Meadow (WM)

10b. Poorly drained ... Meadow (M)

9b. Soil not very poorly or poorly drained ... Subirrigated (Sb) 
(e.g., Table 2). The different ecological sites should then reflect differences in land that are potentially important to users, such as different ecological potential or different management needs.

\section{Step 6: Develop Ecological Site Descriptions}

Once the set of ecological sites has adequate data support, then more detailed data can be gathered from locations that represent the variety of uses and services that can be expected from the site. These locations will serve as the type localities for an individual ecological site that precisely describe the properties of reference communities and states or alternative states. High-intensity samples ${ }^{1,3}$ from reference communities should "typify" the ecological site concept. Reference samples should include photographs, GPS waypoints, field notes, and line-point intercept data (if this hasn't been collected yet at this data location), as well as production sampling and estimates for all species (including trees and shrubs), a full soil profile characterization including dynamic soil properties, and a plant census to capture species that are rare. Plant community dynamics within states also should be monitored. In addition, measurements representing other ecosystem services, including wildlife habitat potential and soil carbon, can be gathered to aid in the development of ecological site interpretations.

Together, these data and additional interpretations are used to produce the ecological site description document. This document should represent the soil, topographic, and other properties distinguishing the ecological site from others. It should convey the key structures and processes of the ecological site, show relationships to other ecological sites, and describe how ecological processes maintain reference and alternative states. Finally, they should contain information on the functions that these processes support, such as grazing use, wildlife habitat, and carbon sequestration potential. Some of these functions (e.g., carbon sequestration) commonly are not now described but might be in the future as demand for such information increases.

\section{Conclusion}

The procedures used to develop ESDs and the form of ESD documents and associated databases currently are in a state of flux in the United States. Interagency protocol documents currently are being developed, so the steps described here represent those that we have used successfully and do not necessarily represent the details that might be adopted in future protocols. Nonetheless, the general sequence described, including research, reconnaissance, concept development, data collection, testing of concepts, concept refinement, and the gathering of detailed measurements for final ESDs will continue to be important parts of the ecological site development process.

\section{References}

1. Bestelmeyer, B. T., A. J. Tugel, G. L. Peacock, Jr., D. G. Robinett, P. L. Shaver, J. R. Brown, J. E. Herrick, H. Sanchez, and K. M. Havstad. 2009. State-and-transition models for heterogeneous landscapes: a strategy for development and application. Rangeland Ecology \& Management 62:1-15.

2. USDA Natural Resources Conservation Service. 2007. National range and pasture handbook. 190-VI, revision 1. Washington, DC, USA: US Department of Agriculture.

3. Tugel, A. J., S. A. Wills, and J. E. Herrick. 2008. Soil change guide: procedures for soil survey and resource inventory. Version 1.1. Lincoln, NE, USA: USDA, Natural Resources Conservation Service, National Soil Survey Center.

Authors are State Rangeland Ecologist, USDA-Natural Resources Conservation Service (NRCS) California State Office, Davis, CA 95616, USA, Kendra.Moseley@ca.usda.gov (Moseley); Rangeland Management Specialist, USDA-NRCS, West National Technology Support Center, Portland, OR 97232, USA (Shaver); Rangeland Management Specialist, USDANRCS, Central National Technology Support Center, Fort Worth, TX 76115, USA (Sanchez); and Research Ecologist, USDA-Agricultural Research Service Jornada Experimental Range, Las Cruces, NM 88003, USA (Bestelmeyer). 